\title{
Does genetic distance between parental species influence outcomes of hybridization among coral reef butterflyfishes?
}

\author{
STEFANO R. MONTANARI ${ }^{*} \dagger$ JEAN-PAUL A. HOBBS, + MORGAN S. PRATCHETT, $\S$ \\ LINE K. BAY $₫$ and LYNNE VAN HERWERDEN $\uparrow^{* *}$ \\ *AIMS@JCU, Australian Institute of Marine Science, School of Marine and Tropical Biology, James Cook University, \\ Townsville, Qld 4811, Australia, †Centre for Sustainable Tropical Fisheries and Aquaculture, James Cook University, \\ Townsville, Qld 4811, Australia, †Department of Environment and Agriculture, Curtin University, Perth, WA 6845, \\ Australia, §ARC Centre of Excellence for Coral Reef Studies, James Cook University, Townsville, Qld 4811, Australia, \\ -Australian Institute of Marine Science, PMB 3, Townsville MC, Townsville, Qld 4810, Australia, **School of Marine \\ and Tropical Biology, James Cook University, Townsville, QLD 4811, Australia
}

\begin{abstract}
Christmas Island is located at the overlap of the Indian and Pacific Ocean marine provinces and is a hot spot for marine hybridization. Here, we evaluate the ecological framework and genetic consequences of hybridization between butterflyfishes Chaetodon guttatissimus and Chaetodon punctatofasciatus. Further, we compare our current findings to those from a previous study of hybridization between Chaetodon trifasciatus and Chaetodon lunulatus. For both species groups, habitat and dietary overlap between parental species facilitate frequent heterospecific encounters. Low abundance of potential mates promotes heterospecific pair formation and the breakdown of assortative mating. Despite similarities in ecological frameworks, the population genetic signatures of hybridization differ between the species groups. Mitochondrial and nuclear data from $C$. guttatissimus $\times C$. punctatofasciatus $(1 \%$ divergence at cyt $b)$ show bidirectional maternal contributions and relatively high levels of introgression, both inside and outside the Christmas Island hybrid zone. In contrast, $C$. trifasciatus $\times$ C. lunulatus (5\% cyt $b$ divergence) exhibit unidirectional mitochondrial inheritance and almost no introgression. Back-crossing of hybrid C. guttatissimus $\times$ C. punctatofasciatus and parental genotypes may eventually confound species-specific signals within the hybrid zone. In contrast, hybrids of $C$. trifasciatus and $C$. lunulatus may coexist with and remain genetically distinct from the parents. Our results, and comparisons with hybridization studies in other reef fish families, indicate that genetic distance between hybridizing species may be a factor influencing outcomes of hybridization in reef fish, which is consistent with predictions from terrestrially derived hybridization theory.
\end{abstract}

Keywords: Chaetodontidae, Christmas Island, hybrid ecology, introgression, NEWHYBRIDS, STRUCTURE

Received 4 September 2013; revision received 15 April 2014; accepted 16 April 2014

\section{Introduction}

Hybridization is often a significant evolutionary force that can erode genetic diversity in natural populations

Correspondence: Stefano R. Montanari, Fax: +61 74781 5511;

E-mail: stefanomontanari@gmail.com
(Abbott et al. 2013), but can also contribute to creating and maintaining genotypic novelty (Seehausen 2004; Mallet 2007; Nolte \& Tautz 2010; Abbott et al. 2013). Hybridization challenges the assumptions of the biological species concept: to provide a suitable framework for the interpretation of natural hybridization (Frankham et al. 2012), we define species as separate 
'genotypic clusters' that remain stable in the face of gene flow (Mallet 2007). Hybridization can increase genotypic variation, which may be significant in enhancing adaptation to altered or novel environments (e.g. Darwin finches - Grant \& Grant 2002). Further, hybridization can have significant effects on evolution through the formation of hybrid swarms (e.g. sticklebacks - Taylor et al. 2006) and stable hybrid lineages, which coexist in sympatry with parental species (e.g. sparrows - Hermansen et al. 2011). Albeit well understood in terrestrial and freshwater systems, the role of hybridization in shaping the evolution of marine organisms remains, with a few exceptions (e.g. corals - Willis et al. 2006), in need of thorough evaluation.

Several ecological and behavioural processes promote natural hybridization (Willis et al. 2013). Closely related species often share similar ecological niches (habitat, diet), and this can increase the frequency of heterospecific encounters (e.g. fire-bellied toads - MacCallum et al. 1998). Species in low abundance may choose to mate with close relatives when conspecific partners are not available; thus, rarity of one or both species within the contact zone might result in the formation of heterospecific social groups (e.g. Grant \& Grant 2008), the breakdown of assortative mating (Arnold 1997) and hybridization. Through ecological observations, the abovementioned studies have identified conditions that favour hybridization in terrestrial systems, but quantitative ecological data are scarce in the marine hybridization literature (Montanari et al. 2012).

Studies have shown a negative correlation between frequency of hybridization and evolutionary divergence (Edmands 2002; Mallet 2005, 2007): genetic distance, with some exceptions (Edmands 2002), is considered a good predictor of reproductive isolation (Singhal \& Moritz In press). Further, interspecific gene flow mediated by hybridization (introgression) can occur between species with varying levels of divergence, but appears to be strongest in more closely related species (Mallet 2005). The evolutionary proximity of the parental species facilitates hybridization because closely related species are more likely to be genetically compatible and therefore capable of producing viable hybrids (Mallet 2005). Conversely, if divergence is too extensive, successful hybridization might not be possible due to genetic incompatibility (Mallet 2005; Abbott et al. 2013). Geographical locations where hybridization is most prevalent are ideal to investigate the outcomes of hybridization in taxa with varying degrees of relatedness, because these narrow areas allow controlling for environmental variation that may influence patterns of hybridization (Avise 2000).

Suture zones are geographical locations where hybrid zones naturally cluster (Swenson \& Howard 2004) and were defined by Remington (1968) as '[bands] of geographical overlap between major biotic assemblages, including some pairs of species or semi-species which hybridize in the zone'. In terrestrial suture zones, the extent of divergence and reproductive isolation between hybridizing species can vary greatly and influence the evolutionary consequences of hybridization (Moritz et al. 2009): here, we propose to test this terrestrially derived notion in marine species.

The best-known tropical marine suture zone is located at the Indo-Pacific biogeographical border, in the eastern Indian Ocean (Hobbs et al. 2009). Here, the fish fauna is characterized by an admixture of Indian and Pacific Ocean taxa (Hobbs \& Salmond 2008). Typically allopatric sister species make secondary contact at this border, where they form the highest number of reef fish hybrids reported from any marine location (Hobbs et al. 2009). Christmas Island, Australia, is an oceanic seamount located on the Indo-Pacific biogeographical border (Allen et al. 2007), and its reefs provide a unique location to apply terrestrially derived theory to test ecological frameworks and evolutionary consequences of hybridization in a tropical marine suture zone.

Butterflyfishes inhabit coral reefs worldwide, are dependent on live coral for food (Cole et al. 2008) and shelter (Wilson et al. 2013), readily respond to changes in reef environments (Pratchett et al. 2008) and thus are ideal candidates to examine effects of hybridization on adaptation (Grant \& Grant 2002). Butterflyfishes are well known for their propensity to hybridize, with more than $50 \%$ of species in the family involved in heterospecific pairing and/or interbreeding (Hobbs et al. 2013). Hybrids occur mostly along zones where major biogeographical provinces overlap (Hobbs et al. 2013), including at least eight butterflyfish species that form hybrids at Christmas Island (Hobbs et al. 2009, 2013). Chaetodon butterflyfishes are an ideal system to investigate reef fish hybridization because many species are monogamous (Yabuta 1997; Pratchett et al. 2006a). Further, even though there may be instances where hybrids go undetected (Hobbs et al. 2013), butterflyfish hybrids are generally easy to recognize through intermediate coloration (McMillan et al. 1999; Montanari et al. 2012; Hobbs et al. 2013).

In a previous study of hybridization between Chaetodon trifasciatus and Chaetodon lunulatus at Christmas Island (Montanari et al. 2012), we hypothesized that the magnitude of divergence between hybridizing parents might influence patterns of introgression in reef fishes based on comparisons of our results to those from the literature (incorporating several geographical locations and reef fish families). By examining hybridization between Chaetodon guttatissimus Bennett, 1832 and Chaetodon punctatofasciatus Cuvier, 1831 at the Indo-Pacific 
marine suture zone, the present study allows us to control for taxon- and location-specific factors that may influence patterns of introgression in reef fishes. Therefore, the aims of this article are to (i) determine the ecological and behavioural context of hybridization between C. guttatissimus and C. punctatofasciatus by assessing abundance, spatial and dietary overlap, and breeding pair formation in parental species and hybrids; (ii) investigate the genetic mechanisms and evolutionary consequences of hybridization between these species through analyses of mitochondrial (mt) and nuclear microsatellite DNA; (iii) discuss similarities and differences in ecology, genetics and potential evolutionary trajectories of C. guttatissimus $\times$ C. punctatofasciatus and $C$. trifasciatus $\times$ C. lunulatus (Montanari et al. 2012) at the Indo-Pacific suture zone. Specifically, we evaluate whether genetic distance between hybridizing species influences maternal inheritance and introgression in tropical marine fish.

\section{Material and methods}

\section{Study location and species}

This study was conducted in October-November 2010 at Christmas Island, Australia, in the northeastern Indian Ocean $\left(10^{\circ} 25^{\prime}-10^{\circ} 34^{\prime} \mathrm{S}, 105^{\circ} 32^{\prime}-105^{\circ} 42^{\prime} \mathrm{E}\right)$ (Fig. 1, inset). The peppered butterflyfish, Chaetodon guttatissimus (Fig. 2A), is wide-ranging in the Indian Ocean, occurring from the East coast of Africa to the Indo-Pacific biogeographical border at Christmas and Cocos (Keeling) Islands (Allen et al. 1998) (Fig. 1). The spot-band butterflyfish,

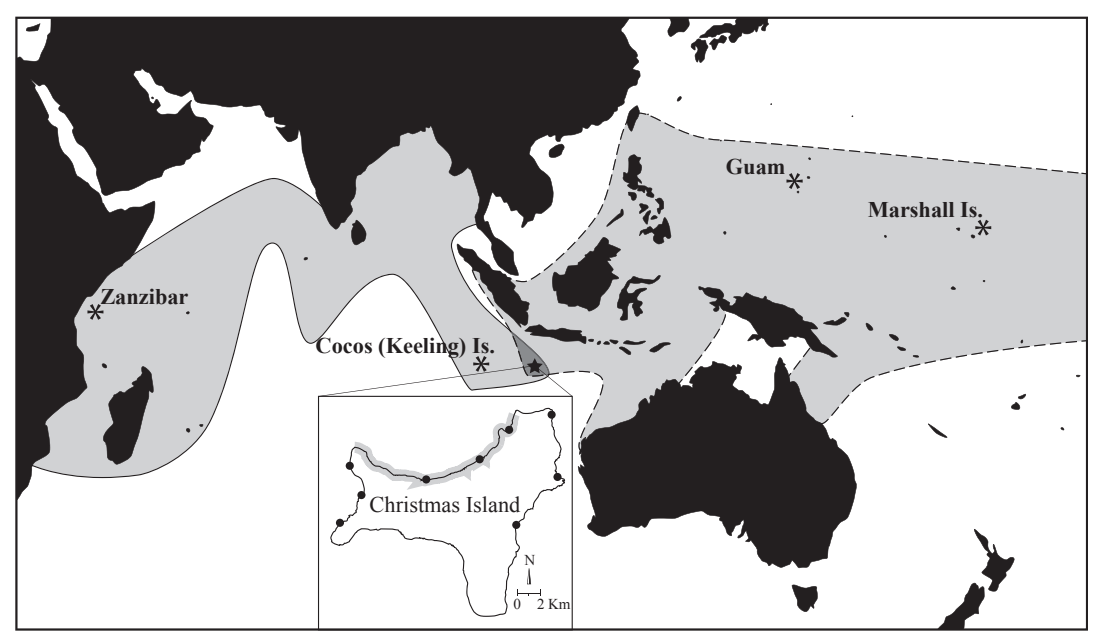

Fig. 1 Map showing the distribution of Chaetodon guttatissimus (solid line) and Chaetodon punctatofasciatus (dashed line), in the Indian and Pacific Oceans, respectively. Asterisks represent sampling locations outside the Christmas Island hybrid zone (detailed sample sizes are given in Material and Methods). The star symbol identifies the position of Christmas Island within the area of overlap (darker shade of grey) between the two species. Inset shows details of the Christmas Island study sites used for the distribution surveys (black circles) and north coast area covered during the Global Positioning System-assisted surveys (thicker grey line).
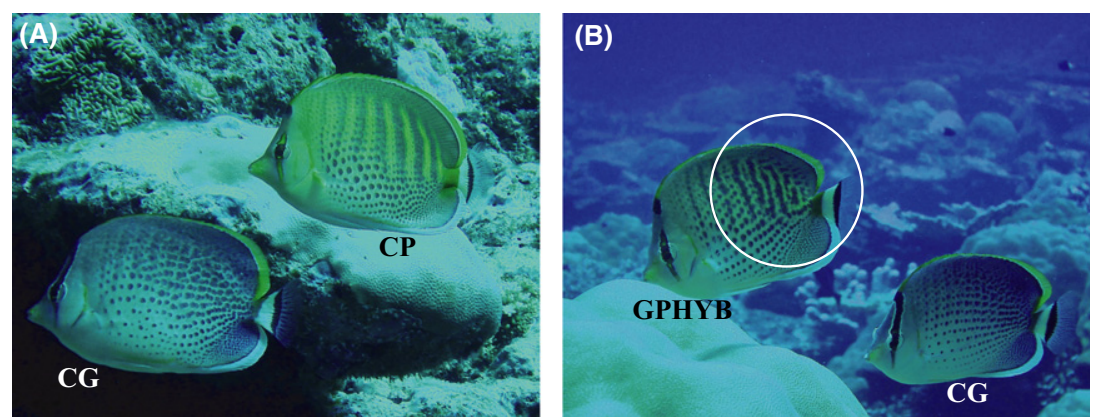

Fig. 2 (A) Chaetodon guttatissimus (CG) and Chaetodon punctatofasciatus (CP) observed in a heterospecific pair at Christmas Island. (B) A hybrid (GPHYB) of this species complex, paired with C. guttatissimus (CG) at Christmas Island: the circle highlights the distinguishing maze-like dorsal pattern (cf the clear, straight lines of C. punctatofasciatus in photograph A). Maze-like patterns, such as these, have been shown to be characteristic of natural fish hybrids (Miyazawa et al. 2010). 
Chaetodon punctatofasciatus (Fig. 2A), is distributed throughout the Western Pacific Ocean, from Indonesia to the Line Islands and from the Ryukyu Islands to the Great Barrier Reef (Allen et al. 1998) (Fig. 1). Christmas Island is the edge of the respective distributions of these butterflyfishes (Allen et al. 1998; Hobbs \& Salmond 2008) (Fig. 1), which form heterospecific pairs at this location (Hobbs et al. 2009) (Fig. 2A). Importantly, putative hybrids with coloration intermediate to C. guttatissimus and C. punctatofasciatus (Fig. 2B) are seen at Christmas Island.

\section{Hybrid zone ecology}

Abundance, depth distribution, and diet surveys. To assess the abundance of all taxa, underwater visual censuses (UVCs) were conducted at nine sites along the accessible coasts (Fig. 1). In face of the relative rarity of the focal species, transect size was increased (Thompson 2004) during additional abundance surveys along the north coast (Fig. 1). Transect length varied (ranging from 162.1 to $580.5 \mathrm{~m}$ ), but all data were standardized, with densities presented as the number of fishes per $3000 \mathrm{~m}^{2}$. Surveyors swam unidirectionally along depth contours while towing a body board fitted with a Global Positioning System (GPS) receiver. The total area sampled for each of 14 replicate transects was calculated based on independent measures of each GPS track (see Data S1, Supporting Information); $t$-tests were used to assess significant differences in abundance between parental species and hybrids.

To assess depth distribution of the parent species and hybrids, the depth at which individual fishes were first sighted was recorded during UVCs $(n=30$ individuals for all taxa). Depth data were examined using a oneway analysis of variance (ANOVA), comparing the mean depth occupied by parent species and hybrids.

In situ 3-minute feeding observations (following Pratchett 2005) were conducted for all individuals recorded during the depth distribution UVCs. To examine dietary overlap between parent species and hybrids, we recorded the number of bites taken from different benthic prey or substrates. Prey items included predominantly scleractinian corals that were categorized based on genus and growth form sensu Montanari et al. (2012). Dietary composition was analysed using a multivariate analysis of variance (MANOVA), comparing the proportion of bites taken from each prey category by the parents and hybrids. Feeding rates (number of bites over $3 \mathrm{~min}$ ) were compared between parents and hybrids using a one-way ANOVA, to further identify differences (if any) in feeding behaviour.

Pairing behaviour surveys. During UVCs along the north coast, pair composition was recorded to determine the frequency of assortative pairing behaviour in the C. guttatissimus group. Pairings were noted for all focal fishes encountered, regardless of whether both partners were within the transect area, and therefore included in the abundance counts. Unpaired fishes were small ( $<70 \mathrm{~mm}$ TL) and most likely juveniles. For each parent species and hybrids, expected pairing frequencies were calculated by multiplying the proportional observed abundances by the number of paired individuals, and observational data were analysed for departures from expectations using a chi-square-test.

\section{Hybrid zone genetics}

Sampling and DNA extraction. Samples of C. guttatissimus $(n=25), C$. punctatofasciatus $(n=18)$ and C. guttatissimus $\times$ C. punctatofasciatus hybrids $(n=16)$ were collected within the Christmas Island hybrid zone. Chaetodon guttatissimus samples from outside the hybrid zone were collected at Cocos (Keeling) Islands $(n=18)$ and Zanzibar $(n=1)$. Similarly, putative purebred C. punctatofasciatus were collected from the Marshall Islands $(n=7)$ and Guam $(n=1)$ in the Pacific Ocean. Individual fish were speared whilst SCUBA diving and fin clips were preserved in $80 \%$ ethanol for later genetic analysis. Purebred parental species from locations as far as $7500 \mathrm{~km}$ away from the hybrid zone were useful in phylogenetic analyses, to tease apart species-specific genetic signals from the signal obtained from the hybrid zone. Chaetodon citrinellus from Lizard Island were used to root all phylogenetic analyses described below (Fessler \& Westneat 2007). DNA was extracted from fin clips using 5\% Chelex-100 (Walsh et al. 1991).

MtDNA sequences and microsatellite genotypes. Mitochondrial cytochrome (cyt) $b$ primers (McMillan \& Palumbi 1995), previously utilized in hybridization studies of Chaetodon butterflyfishes (Montanari et al. 2012), were used to amplify 566 bp of the cyt $b$ gene in all samples. Sequences from Montanari et al. (2012) were also used to redraw the relevant haplotype network. Polymerase chain reactions (PCR), PCR evaluation, product purification, sequencing, alignment and manual editing were conducted as described in Montanari et al. (2012). Twenty microsatellite markers developed for C. punctatofasciatus (Montanari et al. 2013) were used to further examine hybridization in the C. guttatissimus $\times$ C. punctatofasciatus group. PCR and genotyping were performed as described in Montanari et al. (2013).

Phylo- and population genetic analyses. To identify species-specific and hybridization signals, phylogenetic relationships were inferred using four approaches: 
neighbour-joining (NJ), maximum parsimony (MP), Bayesian inference (BI) and maximum likelihood (ML). All phylogenetic model parametrizations and cyt $b$ haplotype network constructions were carried out following Montanari et al. (2012) to allow direct comparisons and minimize model-related variation (see Data S1, Supporting Information). Population genetic analyses followed the same protocols as described in Montanari et al. (2012) and did not include Zanzibar C. guttatissimus $(n=1)$ or Guam C. punctatofasciatus $(n=1)$, due to small sample sizes (see Data S1, Supporting Information).

Microsatellite genotypes were partitioned into clusters assuming an admixture model with independent allele frequencies between populations, using STRUCTURE v2.3.4 (Pritchard et al. 2000). Each value of $k$ (set from 1 to 10) was independently evaluated 20 times, with 1500000 iterations following a 100 000-long burnin (Gilbert et al. 2012). The best fit model was chosen with the Evanno method (Evanno et al. 2005) implemented in STRUCTURE HARVESTER v0.6.93 (Earl \& vonHoldt 2012), and values of $\Delta k$ plotted and presented as Supporting Information. Admixture coefficients (Q), averaged over the 20 independent runs, were visualized by means of a barplot with credibility regions for $k=2$ (corresponding to the parental species irrespective of geographical origin). Posterior probabilities, based on microsatellite genotypes, of individuals belonging to six classes (pure parental species, F1 or F2 hybrids and backcrosses in either direction) were calculated using NEWHYBRIDS (Anderson \& Thompson 2002). Populations outside the hybrid zone were designated as pure parental species as prior information, and the chain was run for 1500000 iterations, after 150000 burn-ins. Probabilities were subsequently averaged at population level. A discriminant analysis of principal components
(DAPC) (Jombart et al. 2010) was run on all loci to investigate the relationship between the sampled populations.

The STRUCTURE, NEWHYBRIDS and DAPC analyses described above were also run on genotypes from Montanari et al. (2012) and added as Supporting Information. By choosing a number of PCs equal to the number of individuals divided by three and a number of DA eigenvectors corresponding to the number of populations minus one in both analyses, the genotypic variability retained in DAPC was similar between the two hybridizing butterflyfish groups. This allowed direct comparisons, thus highlighting key differences in the evolutionary consequences of hybridization in the two Chaetodon species groups at the Christmas Island suture zone.

\section{Results}

\section{Hybrid zone ecology}

Abundance, depth distribution and diet. Hybrid Chaetodon guttatissimus $\times$ Chaetodon punctatofasciatus were relatively common at Christmas Island $(2 \pm 0.47 \mathrm{SE}$ individuals per $3000 \mathrm{~m}^{2}$ ) and at least as abundant as the least common parental species, C. punctatofasciatus $(2 \pm 0.47 \mathrm{SE})\left(t_{(26)}=0.42, P=0.68\right)$ (Table 1$)$. Chaetodon guttatissimus was significantly more abundant (40 \pm 4.5 SE) than C. punctatofasciatus $\left(t_{(13)}=8.32, \quad P<0.0001\right)$ (Table 1).

The ecology (specifically habitat use and dietary composition) of C. guttatissimus, C. punctatofasciatus and their hybrids was very similar. There was no significant difference in depth distribution between C. guttatissimus (average depth $16.6 \mathrm{~m} \pm 0.49 \mathrm{SE}$ ) and C. punctatofasciatus (15.5 $\mathrm{m} \pm 0.49 \mathrm{SE})\left(F_{1,89}=3.14, P=0.08\right)$ (Table 1$)$.

Table 1 Qualitative summary of ecological and behavioural conditions conducive to hybridization in two pairs of allopatric Chaetodon sister species in secondary contact at the Christmas Island suture zone in the Indo-Pacific. Data for the Chaetodon trifasciatus group are summarized from Montanari et al. (2012) and presented here for comparison

\begin{tabular}{lll}
\hline & Chaetodon guttatissimus group & C. trifasciatus group \\
\hline Parental species abundance & One parent rare $\left(2\right.$ individuals per $\left.3000 \mathrm{~m}^{2}\right)$ & Both parents rare $\left(<2\right.$ individuals per $\left.3000 \mathrm{~m}^{2}\right)$ \\
Hybrid abundance & As abundant as rare parent & Rarer than both parents \\
Parental depth distribution & Range: $13-17 \mathrm{~m}$; largely overlapping $(>93 \%)$ & Range: 5-8 m; largely overlapping $(>98 \%)$ \\
Hybrid depth distribution & Overlapping $(>99 \%)$ with parents & Overlapping $(83 \%)$ with parents \\
Parental species diet & Generalist corallivores; largely overlapping & Generalist corallivores; largely overlapping \\
& $(>73 \%)$ & $(>77 \%)$ \\
Hybrid diet & Generalist corallivore; overlapping $(>76 \%)$ with & Generalist corallivore; overlapping $(>81 \%)$ with \\
& parents & parents \\
Parental species pairing & Nonassortative & Nonassortative \\
behaviour & Pairing with both parents; nonassortative & Pairing with both parents; nonassortative \\
Hybrid pairing behaviour & & \\
\hline
\end{tabular}


The parental species occupied relatively narrow, largely overlapping, depth ranges (Table 1). The depth distribution of the hybrids ( $16.2 \mathrm{~m} \pm 0.50 \mathrm{SE}$ ) was not statistically different from that of either parent species $\left(F_{2,29}=1.47, P=0.235\right)$. Similarly, dietary composition was not significantly different between parent species

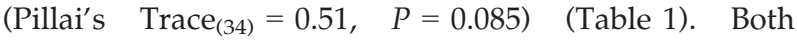
parental species most frequently fed on encrusting Montipora and massive Porites, which are among the most common coral genera at Christmas Island. The hybrids fed largely on the same prey as their parental species (Pillai's Trace $_{(34)}=0.51, P=0.085$ ) (Table 1). The feeding rates (number of bites per $3 \mathrm{~min}$ observation) of parent species and hybrids were not significantly different $\left(F_{2,29}=2.03, P=0.14\right)$.

Pairing behaviour. The relative number of individuals that paired with conspecifics, heterospecifics or hybrids was generally proportional to the abundance of these individuals (Fig. 3A, Table 1). The pairing behaviour of C. punctatofasciatus did not significantly deviate from the frequencies expected based on abundances $\left(\chi_{(2, n=30)}^{2}=2.89, P>0.24\right)$, indicating that this species is pairing nonassortatively under these conditions (Fig. 3A, Table 1). Chaetodon guttatissimus appeared to actively choose to pair heterospecifically (disassortative mating $)\left(\chi_{(2, n=264)}^{2}=14.91, P<0.001\right)$, but this may be a statistical artefact of the large sample size for this species (Fig. 3A). Hybrids were never observed paired together and formed pairs with the parental species nonassortatively $\left(\chi_{(2, n=26)}^{2}=3.25, P>0.19\right) \quad$ (Fig. 3A). This indicates that hybrids are likely choosing partners based on their prevalence rather than phenotype.

\section{Hybrid zone genetics}

Five hundred and sixty-six base pairs (bp) of the mitochondrial cyt $b$ region were resolved for a total of 86 individuals in the C. guttatissimus group. The alignment contained 92 parsimony informative sites and identified 49 discrete haplotypes (Fig. 3B). Twenty microsatellite loci reliably amplified and were scored in 83 individuals: one C. punctatofasciatus from Christmas Island was excluded due to $>20 \%$ missing data. Population level tests showed significant departures from HWE in 26 of 100 tests after sequential Bonferroni correction $(\alpha=0.01)$ (Table S1, Supporting information). Eighteen $(69 \%)$ of these HWE departures were concentrated at five loci (Cpun3, 4, 7, 9 and 13) (Table S1, Supporting information). Null alleles contributed to departures from HWE in all abovementioned loci. Chaetodon punctatofasciatus from Christmas Island had the most private alleles (17) compared with all other taxa in this group (Table S1, Supporting information).

\section{Phylogenetic relationships}

Congruent phylogenetic relationships were inferred with four methodologies (NJ, MP, BI and ML), and a clear separation between the two parental clades was strongly supported by all analyses (Fig. 3B). Six fixed nucleotide changes ( $1 \%$ divergence at cyt $b$ ) separated the two parental species, despite evidence of some interspecific mtDNA exchange (Fig. 3B). All C. punctatofasciatus individuals and three of 44 individuals $(7 \%)$ identified in the field as C. guttatissimus based on coloration were contained in a single clade (Fig. 3B). Two of these individuals were from Cocos (Keeling) Islands, outside the hybrid zone of Christmas Island (Fig. 3B). Hybrids in the C. guttatissimus group shared haplotypes with both parental clades, indicating a bidirectional maternal contribution to hybridization (Fig. 3B). This contrasts with the Chaetodon trifasciatus group, where redrawn haplotype relationships from Montanari et al. (2012) show 5\% divergence between the parent species at cyt $b$, and all hybrids occur in only one of the two parental clades (unidirectional maternal contribution Fig. S1B, Supporting information).

\section{Population genetic structure}

Cytochrome $b$ haplotype $(h)$ and nucleotide $(\pi)$ diversities, as well as gene diversity based on microsatellites (1-Q inter) within the Christmas Island hybrid zone, were high for all taxa in the C. guttatissimus group (Table S2, Supporting information). The AMOVA fixation index for mtDNA cyt $b$ was $\Phi_{\text {st }}=0.48 P<0.0001$. Microsatellites indicated a clear separation between parental species and hybrids and had raw $F_{\mathrm{st}}=0.038$, $P<0.0001, D_{\text {est }}=0.115$ and ENA-corrected values that were comparable to raw values, indicating low confounding effects from null alleles (Table S4, Supporting information). Nearly all pairwise $F_{\text {st }}$ tests were significant for mitochondrial and nuclear markers, and this was further confirmed with $D_{\text {est }}$ (Table S3, Supporting information). Genetic structure was evident between parental species irrespective of geographical location (Tables S3, Supporting information). Analyses of cyt $b$ did not detect significant intraspecific structure between populations of either C. guttatissimus or C. punctatofasciatus (Table S3A, Supporting information). Microsatellites indicated weak intraspecific structure between C. guttatissimus populations, but not between C. punctatofasciatus populations (Table S3B, Supporting information), possibly due to small sample size of the Marshall Island population. The hybrid population significantly differed from all other populations (Table S3, Supporting information). Mitochondrial data indicated that hybrids are less differentiated from the parental species 
(A)

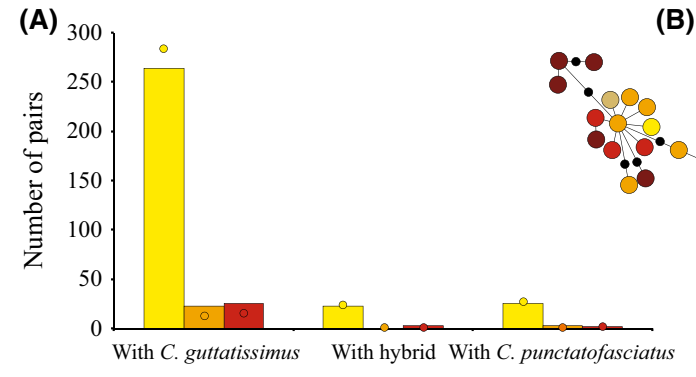

(C)

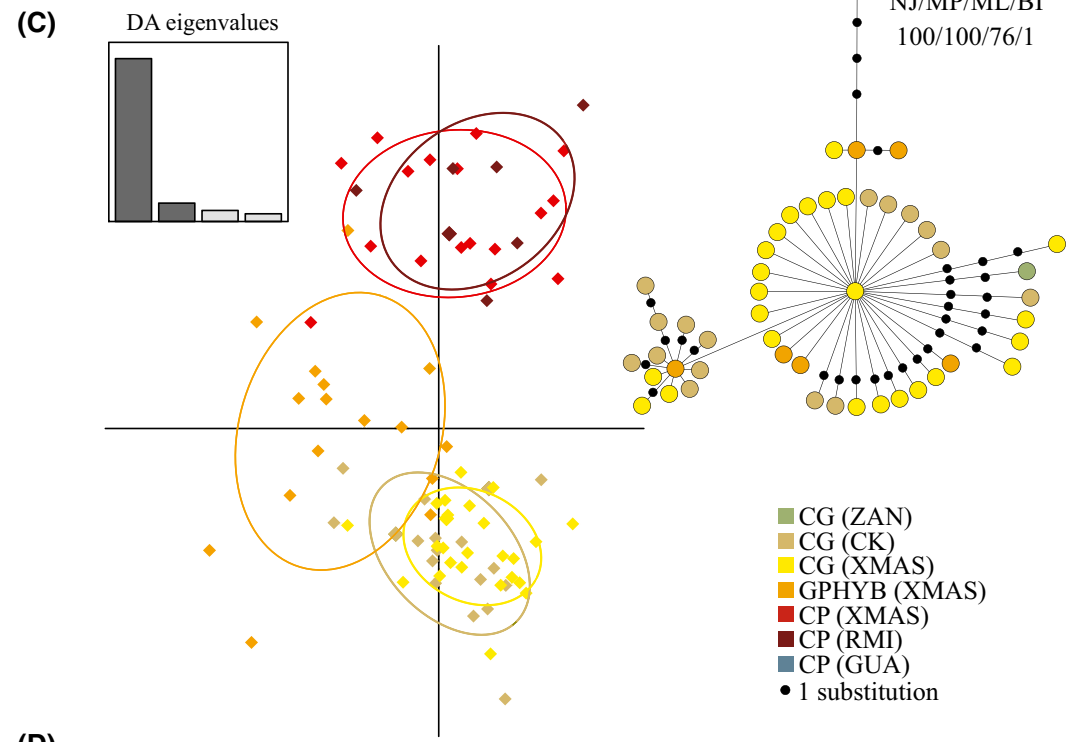

(B)

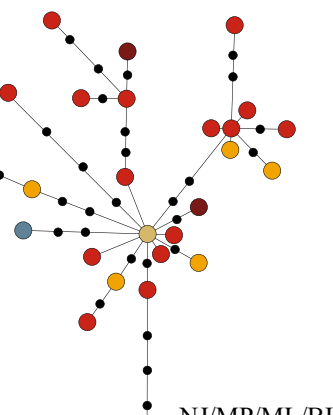

ML/B

$100 / 100 / 76 / 1$

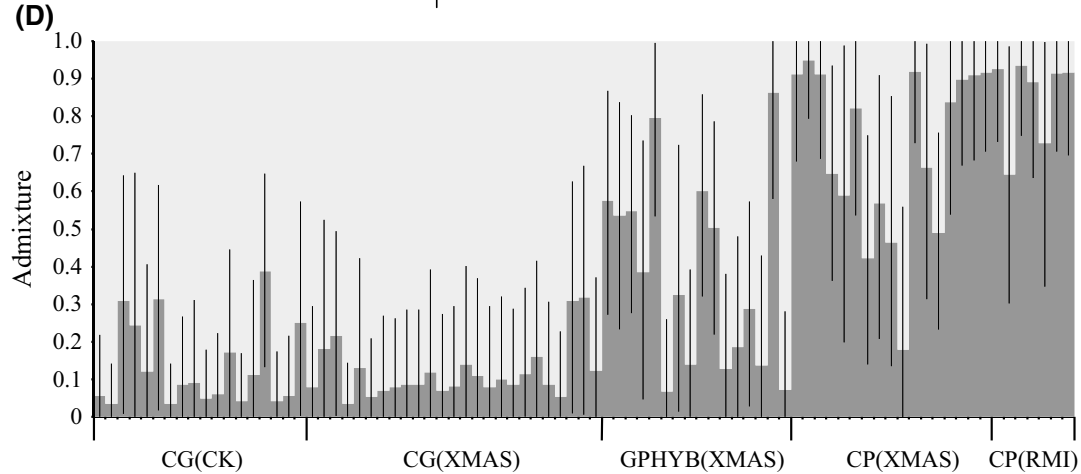

Fig. 3 (A) Pairing frequencies of Chaetodon guttatissimus (yellow), C. guttatissimus $\times$ Chaetodon punctatofasciatus hybrids (orange) and C. punctatofasciatus (red). All three taxa are colour-coded according to the legend below. Bars represent observed pairings from Christmas Island, and dots represent expected pairing frequencies based on observed taxon abundance. Observed pairing does not statistically deviate from expectations, indicating that taxa are pairing nonassortatively. (B) MST showing haplotype relationships in the C. guttatissimus group. Each circle represents one individual and is colour-coded for taxon and geographical origin. Each black dot on connecting branches represents one substitution (bp). Bootstrap support values for phylogenetic relationships inferred by NJ, MP, maximum likelihood and posterior probabilities from BI are shown for the partition between the two major clades in the species group. (C) Scatterplot of DAPC (Jombart et al. 2010) performed on 20 microsatellite loci for five populations of the C. guttatissimus group. Populations are shown by colours and 95\% inertia ellipses, squares represent individual genotypes. Axes show the first two discriminant functions, and eigenvalues the genetic information retained by discriminant functions. (D) Barplot of STRUCTURE admixture coefficients based on 20 microsatellite loci in five populations of the C. guttatissimus group. Bars represent individuals, black lines are $90 \%$ credibility regions, and subdivisions show the genotypic admixture between clusters $(k=2$, representing the parent species). Colour coding as well as taxon and geographical location abbreviations are valid throughout all panels: CG, C. guttatissimus; CP, C. punctatofasciatus; GPHYB, C. guttatissimus $\times$ C. punctatofasciatus; CK, Cocos (Keeling) Islands; GUA, Guam; RMI, Republic of Marshall Islands; XMAS, Christmas Island; ZAN, Zanzibar. 
within the hybrid zone (Table S3A, Supporting information). However, microsatellite data showed that the hybrids are less differentiated from C. punctatofasciatus within the hybrid zone, but more from C. guttatissimus (Table S3B, Supporting information).

STRUCTURE identified two clusters (Fig. S2A, Supporting information): some admixture was detected between parental species (Fig. 3D), both outside and within the hybrid zone - consistent with previous mtDNA and microsatellite analyses. Interestingly, the C. guttatissimus population from Cocos (Keeling) showed a slightly higher level of admixture with C. punctatofasciatus than the Christmas Island population (Fig. 3D). Most notably, the C. punctatofasciatus population in the contact zone showed greater levels of admixture than C. guttatissimus (Fig. 3D), but with high levels of variability in the estimates. The hybrids' intermediacy was evident compared to both parental species, particularly C. guttatissimus (Fig. 3D). Two clusters were also identified in the $C$. trifasciatus group (Montanari et al. 2012) (Fig. S2B, Supporting information): this data set shows lower levels of parental admixture (particularly in the Chaetodon lunulatus populations) and hybrid intermediacy is clear in this group (Fig. S1D, Supporting information). In both butterflyfish groups, however, STRUCTURE lacks the resolution to reliably detect backcrossing and hybrid classes (possibly as a result of the small sample sizes and limited number of molecular markers).

NEWHYBRIDS assigned over 95\% of C. guttatissimus individuals to their pure species, in both populations of origin (Fig. 4). As also suggested in STRUCTURE, the Cocos (Keeling) population had a somewhat greater probability of introgression than the Christmas Island population (Fig. 4). The hybrids were clearly intermediate and were mostly either assigned to C. guttatissimus or designated as F2 hybrids (Fig. 4). Likewise, a similarly high probability of being F2 hybrids (almost 30\%) was assigned to the Christmas Island population of C. punctatofasciatus, consistent with the suggested pattern of introgression observed in the STRUCTURE analysis (Figs 3D and 4). This contrasts with the C. trifasciatus group (Montanari et al. 2012), in which both parental species were assigned to their respective pure clusters with $>92 \%$ probability irrespective of geographical location (Fig. S3, Supporting information). The hybrids in this group had a range of probabilities of being assigned to either parental cluster, F1, F2 or either backcross (1025\%) (Fig. S3, Supporting information). Moreover, approximately $60 \%$ of assignments were to interparental crosses, the remainder being to pure parental clusters (Fig. S3, Supporting information). In both NEWHYBRIDS analyses, the standard deviation around the mean posterior probabilities was negligible for all taxa, except for the hybrids, underlining the uncertainty associated with assigning these intermediate individuals.

DAPC examined the relationship between clusters, predefined as combinations of taxon and geographical location (Fig. 3C). The hybrid population was distinct from all others, and hybrid genotypes were intermediate between parental species' genotypes (Fig. 3C). Little partitioning was evident between populations of the same species (Fig. 3C), consistent with other analyses. Chaetodon guttatissimus $\times$ C. punctatofasciatus hybrids occupied a broad parameter space close to their parental clusters, and confidence ellipses were shared in seven of 16 individuals (Fig. 3C). In contrast, microsatellite data from Montanari et al. (2012), presented in a reparametrized DAPC (see Material and Methods), show almost no overlap of hybrid and parental genotypes in the C. trifasciatus group (Fig. S1C, Supporting information).

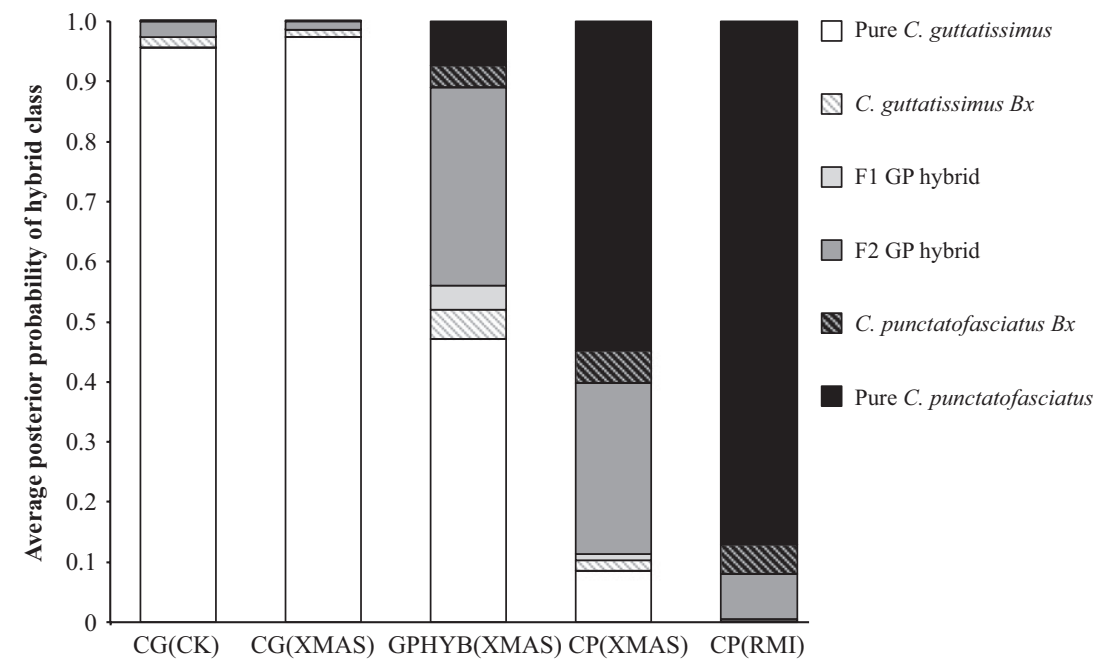

Fig. 4 Posterior probabilities, based on microsatellite data, of individuals of the Chaetodon guttatissimus group belonging to six classes: pure parental species, F1 or F2 hybrids and backcrosses $(B x)$ in either direction. Individual data were averaged within population of origin. Colour codes for the six classes are given in the legend. Each bar represents one population and is designated by species and geographical location (for sample sizes refer to Material and Methods). CG, C. guttatissimus; $\mathrm{CP}$, Chaetodon punctatofasciatus; GPHYB, C. guttatissimus $\times$ C. punctatofasciatus; CK, Cocos (Keeling) Islands; RMI, Republic of Marshall Islands; XMAS, Christmas Island. 


\section{Discussion}

\section{Hybrid zone ecology}

Chaetodon guttatissimus and Chaetodon punctatofasciatus as well as Chaetodon lunulatus and Chaetodon trifasciatus (Montanari et al. 2012) have come into secondary contact at the tropical marine suture zone of Christmas Island. Our results highlight several ecological factors that are likely to contribute to the propensity of these species to hybridize. Some degree of habitat overlap is a necessary precursor to hybridization in sexual vertebrates (e.g. Bombina toads - Vines et al. 2003). The distributions of C. guttatissimus, C. punctatofasciatus and their hybrids largely overlap at Christmas Island: all taxa occupy sites with similar exposure (north coast) and have relatively narrow and consistent depth ranges. Habitat overlap was also reported between C. lunulatus and C. trifasciatus (Montanari et al. 2012) and has been documented for a large number of hybridizing marine fishes (Nichols 1918; Norman 1934; Schultz \& Smith 1936; Gosline 1948; Randall 1956; Feddern 1968; Hettler 1968; Fischer 1980; Rao \& Lakshmi 1993; Frisch \& van Herwerden 2006; Yaakub et al. 2006, 2007; Marie et al. 2007; Hobbs et al. 2013). Such overlap increases the chance of heterospecific encounters between hybridizing butterflyfishes at the Indo-Pacific suture zone.

Chaetodon guttatissimus, C. punctatofasciatus, C. trifasciatus and C. lunulatus are relatively specialized obligate corallivores (Cole et al. 2008; Pratchett 2013), and their feeding mode has been confirmed through both gut content analyses (Harmelin-Vivien 1989; Sano 1989) and direct observations (Pratchett 2005). This study and data from Montanari et al. (2012) indicated that, in each hybridizing group, the two parental species and their respective hybrids fed on the same suite of coral prey. Further, gut content analyses and direct feeding observations in tropical marine fishes belonging to the Acanthuridae (Randall 1956), Pomacanthidae (Feddern 1968) and Serranidae (Fischer 1980) showed, in all cases, that the diets of hybridizing parents and hybrids were essentially the same. In synergy with overlap in habitat use, dietary overlap further increases encounter probability between hybridizing butterflyfishes at Christmas Island.

Rarity of conspecific mates is considered a promoting factor in hybridization among terrestrial organisms (e.g. Darwin finches - Grant \& Grant 2002) and reef fishes (Randall et al. 1977; Pyle \& Randall 1994; van Herwerden et al. 2002; Maruska \& Peyton 2007; Hobbs et al. 2009). Although C. guttatissimus is relatively common at Christmas Island, its sister taxon, C. punctatofasciatus, is rare. At Christmas Island, C. punctatofasciatus occurs in densities 40-100 times lower than those found at locations near the centre of its distribution range (e.g. Indonesia and Palau - Findley \& Findley 2001). The local rarity of C. punctatofasciatus may explain why many of these individuals are found in heterospecific pairs. Chaetodon trifasciatus and C. lunulatus are both rare at Christmas Island (Montanari et al. 2012), and their abundances are one to three orders of magnitude lower compared with any other location for which abundance data are available (Adrim \& Hutomo 1989; Findley \& Findley 2001; Pratchett et al. 2004, 2006b; Pereira \& Videira 2005).

The frequency of heterospecific pair formation was proportional to the abundance of parent species in both the C. guttatissimus and C. trifasciatus (Montanari et al. 2012) hybrid groups at Christmas Island. This supports the hypothesis that rare species (and hybrids) are forming heterospecific pairs based on encounter rates and that a rare species (or hybrid) will choose a partner based on availability rather than the phenotypic identity of the individual. A breakdown in assortative mate choice has been reported for other pair-forming Chaetodon butterflyfishes that are known to hybridize (McMillan et al. 1999; Hobbs et al. 2013). The parent species and hybrids examined in this study and in Montanari et al. (2012) belong to subgenera thought to be exclusively monogamous (Pratchett et al. 2006a; Craig et al. 2010), and indeed, examination of the gonads of heterospecific pairs at Christmas Island revealed that these pairs always comprised a mature male and a mature female (Hobbs unpublished data). Therefore, the observed heterospecific breeding pairs are likely producing the hybrids seen at Christmas Island. Overall, our observations indicate that the ecological and behavioural processes that set the scene for hybridization are similar across Chaetodon butterflyfish hybrid groups at Christmas Island and probably explain the onset of hybridization in pair-forming butterflyfishes elsewhere (Hobbs et al. 2013).

\section{Hybrid zone genetics}

Mitochondrial and nuclear DNA analyses confirmed hybridization in both the C. guttatissimus and C. trifasciatus (Montanari et al. 2012) groups. However, despite similarities in the ecological context of hybridization in the two complexes, the genetic mechanisms are clearly different. In C. guttatissimus - C. punctatofasciatus, which are $1 \%$ divergent at cyt $b$ as measured in this study, hybrids shared mtDNA with both parental clades, indicating bidirectional maternal contribution to hybridization, a mode previously reported in reef fishes (McMillan et al. 1999; van Herwerden and Doherty 2006). This is consistent with field observations of heterospecific pairs in which females were identified as 
either C. guttatissimus or C. punctatofasciatus, but in contrast with unidirectional mitochondrial inheritance in C. trifasciatus $\times$ C. lunulatus, $5 \%$ divergent at cyt $b$ (Montanari et al. 2012). In previous studies of reef fish hybridization, most or all hybrids reportedly shared haplotypes with the more abundant parental species, suggesting sneak mating by males of the rare species with females of the common species, likely due to rarity of conspecifics (van Herwerden et al. 2006; Yaakub et al. 2006; Marie et al. 2007). In both cases of Chaetodon hybridization examined here and in Montanari et al. (2012), hybrids shared most (or all) haplotypes with the rarest of contributing parents. Although this could be an artefact of small samples sizes (inherent to hybridization studies, where hybrid taxa are often rare), females of the rare parent species appear to actively choose to mate with males of the more abundant sister species, probably due to the lack of conspecific males. To discriminate whether these results are consistent with female-mediated partner choice (Wirtz 1999), or represent selection against offspring that result from the opposite cross, further enquiry should be directed towards hybrid fitness in Chaetodon butterflyfish.

Mitochondrial introgression was detected in Christmas Island C. guttatissimus individuals, which shared haplotypes with C. punctatofasciatus. This supports backcrossing of hybrid females with C. guttatissimus males. Microsatellite analyses also showed nuclear introgression in either direction, but mostly towards C. punctatofasciatus. The detection of both mtDNA and nDNA introgression in this group is perhaps not surprising, given the close genetic proximity of the parent species (Mallet 2005). Introgressed individuals were all identified as pure parents based on coloration, indicating that assessment of hybrid abundance based on coloration alone can lead to underestimation (Hobbs et al. 2013). Some 'purebred' C. guttatissimus from Cocos (Keeling) Islands also had C. punctatofasciatus mtDNA and nDNA even though hybrids have never been observed at this location. Larval dispersal from Christmas to Cocos (Keeling) Islands (facilitated by westward flowing surface currents) might explain the presence of these individuals (Yaakub et al. 2006; Craig 2008). Previous studies of reef fish hybridization showed that gene flow between the parent species was either bidirectional or directed from the abundant maternal species to the rare paternal species (McMillan et al. 1999; van Herwerden et al. 2006; Yaakub et al. 2006; Marie et al. 2007). Unidirectional mtDNA introgression (or lack thereof, as in the C. trifasciatus group - Montanari et al. 2012) indicates that a partial barrier to gene flow is still present, perhaps due to assortative mating or selection against hybrids (Rhymer \& Simberloff 1996). Assortative mating is unlikely, because our observations indicate that, in both groups, pairs are formed bidirectionally, and hybrids pair with either parental species, providing the opportunity for backcrossing. Further, the admixture detected in nDNA shows that the historic hybridization suggested by the mtDNA introgression is ongoing and that hybrids are still contributing to interspecific gene flow.

An alternative interpretation of our detection of mtDNA and nDNA introgression between C. guttatissimus and C.punctatofasciatus is incomplete lineage sorting. Recent and robust phylogenies of the Chaetodontidae based on two mtDNA and rRNA markers unequivocally partition the two sister species, suggesting that the lineages have sorted completely (Littlewood et al. 2004; Hsu et al. 2007). Moreover, our phylogenetic analyses have shown that C. guttatissimus and C. punctatofasciatus populations sampled from locations most distant from the hybrid zone have distinct, species-specific mtDNA haplotypes. However, detection of introgressed individuals outside the hybrid zone points to possible incomplete lineage sorting, because allopatric populations of these species show some degree of admixture, irrespective of the geographical distance between them. To discriminate between this scenario and introgressive hybridization, further studies should include more samples across the distribution ranges of these species and apply genotyping-by-sequencing techniques to increase resolution.

\section{Consequences of hybridization}

Contrary to what has been observed in the Solomon Islands-Papua New Guinea hybrid zone involving C. punctatofasciatus and Chaetodon pelewensis (McMillan et al. 1999) and in another hybridizing fish, Acanthurus leucosternon, at Christmas Island (Marie et al. 2007), the introgressive hybridization between C. guttatissimus and C. punctatofasciatus is not strong enough to swamp species-specific signals. Although this pattern could be the result of chance given the small sample size, our data suggest that divergence between C. guttatissimus and C. punctatofasciatus is decreasing within the hybrid zone and gene flow mediated by the hybrids appears to be ongoing. Persistence of hybrids and introgressed individuals at Christmas and Cocos (Keeling) Islands may eventually confound species signals in the C. guttatissimus hybrid group, resulting in a hybrid swarm (sensu Taylor et al. 2006). Alternatively, the presence of novel genotypes (and the high genetic diversity) in the hybrid population at Christmas Island may one day enable hybrids to exploit niches not occupied by parent species. This process was documented in terrestrial (Geospiza Darwin finches - Grant \& Grant 2002) and freshwater environments (cichlids - Seehausen 2004) 
and can lead to the formation of new species (Seehausen 2004). Long-term monitoring of the reef fish suture zone at Christmas Island (Hobbs et al. 2009; Arnold \& Martin 2010), through regular assessment of hybrid prevalence and genotypic make up across a wide range of taxa, could further elucidate the ecological and evolutionary relevance of hybridization in reef fishes.

The scenario emerging from the $C$. trifasciatus hybrid group (Montanari et al. 2012) appears different to that of the C. guttatissimus group. Lack of introgression, evident both in mtDNA and in microsatellites, and unidirectional mtDNA inheritance in the C. trifasciatus group indicate that interspecific gene flow mediated by hybrids is minimal at Christmas Island. Even though failure to detect significant levels of introgression in this group could be due to sample size, the sample sizes in the two groups were similar, leading us to expect similar power of detection in both hybridizing groups. Interestingly, in the $C$. trifasciatus group, a Zanzibar individual identified in the field as $C$. trifasciatus showed almost $2 \%$ divergence at cyt $b$ from its putative species clade (Montanari et al. 2012): this could be a rare backcross with a hybrid formed between $C$. trifasciatus and other members of Corallochaetodon that occur in that area (e.g. C. melapterus - B. Bowen, pers. comm.). This needs further work to be confirmed, but if found to be true could indicate that barriers to gene flow are permeable in Corallochaetodon, despite the apparent lack of backcrossing at Christmas Island (Montanari et al. 2012).

The rarity of both parent species and hybrids in the C. trifasciatus group may prevent detection of introgression and bidirectional maternal contribution at Christmas Island (Montanari et al. 2012). In this group, the measured 5\% divergence at cyt $b$ (Montanari et al. 2012) appears to be large enough to generate genotypic novelty in the form of a persistent sympatric hybrid taxon, albeit small enough to warrant successful hybridization (Mallet 2005). Nuclear microsatellite DNA data were particularly informative for this group, confirming the hybrids' status as hybrids rather than aberrant colorations of C. lunulatus, a possibility not ruled out by previous mtDNA analyses (Montanari et al. 2012). Microsatellites further showed that hybrid genotypes are intermediate and different to those of the parent species, even within the hybrid zone, thus maintaining their genotypic identity despite extensive ecological, behavioural and reproductive contact with parental species. Hybrid genotypes or hybrid species sometimes colonize environments distinct to those of their parents, as observed for example in cichlids and sculpins (Seehausen 2004; Nolte et al. 2006). However, sympatric hybrid coexistence with parental forms does occur (sparrows - Hermansen et al. 2011; swallowtail butterflies - Kunte et al. 2011), and this could be the case for C. trifasciatus $\times$ C. lunulatus hybrids at Christmas Island.

The apparent negative interaction between extent of divergence and introgression highlighted in this study finds further validation when data from other hybridizing reef fishes are examined. As noted in Montanari et al. (2012), for example, in the Solomon Islands, hybridization between C. punctatofasciatus and C. pelewensis (McMillan et al. 1999), divergent by $0.7 \%$ at cyt $b$ (McMillan \& Palumbi 1995), results in extensive bidirectional introgression (McMillan et al. 1999). This interaction holds true even in families other than the Chaetodontidae. In the Labridae, bidirectional introgression was detected in hybridizing Thalassoma jansenii and T. quinquevittatum (Yaakub et al. 2006), divergent by $<2 \%$ at cyt $b$ (Bernardi et al. 2004). Conversely, in Halichoeres garnoti and H. bivittatus, divergent by $>5.5 \%$ based on three mtDNA markers (Barber \& Bellwood 2005), hybridization did not result in introgression (Yaakub et al. 2007). In the Acanthuridae, hybridization between A. leucosternon and Acanthurus nigricans, 1\% divergent at mtDNA COI, was introgressive and bidirectional (Marie et al. 2007). In hybridizing Serranids Plectropomus leopardus and Plectropomus maculatus, 1\% divergent based on two nuclear and two mtDNA markers (Craig \& Hastings 2007), hybridization was highly introgressive, but the maternal contribution was unidirectional (van Herwerden et al. 2006).

Further enquiry should be aimed at evaluating the relative importance of divergence levels in shaping the evolutionary outcomes of reef fish hybridization, and to test whether reef fish have a threshold of divergence beyond which their ability to hybridize is lost, as suggested for terrestrial species (Mallet 2005). Given their position at the Indo-Pacific marine suture zone, Christmas and Cocos (Keeling) Islands could provide an ideal location for these future studies. Further, application of genomic tools may identify adaptive genes that are differentiated between hybridizing reef fish species, which will provide insights into adaptation and selection for hybrid genotypes in environments that are novel compared with those inhabited by the parental species outside the hybrid zone.

\section{Acknowledgements}

This study was financially supported by AIMS@JCU (SRM) and the ARC CoE for Coral Reef Studies (MSP). We thank Giacomo Bernardi, Shane Blowes, Sean Connolly and five anonymous reviewers for comments that improved this manuscript; Jeremiah Plass-Johnson and Ulrich Frye for providing Zanzibar collections; all staff at MEEL Townsville, AGRF Brisbane, GGF Athens and MACROGEN Seoul for assistance with laboratory work, sequencing and genotyping; Parks Australia and Wet $\mathrm{N}^{\prime}$ Dry Adventures for logistic support at Christmas Island. 


\section{References}

Abbott R, Albach D, Ansell S et al. (2013) Hybridization and speciation. Journal of Evolutionary Biology, 26, 229-246.

Adrim M, Hutomo M (1989) Species composition, distribution and abundance of Chaetodontidae along reef transects in the Flores Sea. Netherlands Journal of Sea Research, 23, 85-93.

Allen GR, Steene R, Allen M (1998) A Guide to Angelfishes and Butterflyfishes. Odissey Publishing, Perth, Washington.

Allen GR, Steene R, Orchard M (2007) Fishes of Christmas Island Christmas Island, Indian Ocean. Christmas Island Natural History Association, Christmas Island, Australia.

Anderson EC, Thompson EA (2002) A model-based method for identifying species hybrids using multilocus genetic data. Genetics, 160, 1217-1229.

Arnold ML (1997) Natural Hybridization and Evolution. Oxford University Press, New York.

Arnold ML, Martin NH (2010) Hybrid fitness across time and habitats. Trends in Ecology \& Evolution, 25, 530-536.

Avise JC (2000) Phylogeography. Harvard University Press, Cambridge, Massachusetts.

Barber PH, Bellwood DR (2005) Biodiversity hotspots: evolutionary origins of biodiversity in wrasses (Halichoeres: Labridae) in the Indo-Pacific and new world tropics. Molecular Phylogenetics and Evolution, 35, 235-253.

Bernardi G, Bucciarelli G, Costagliola D, Robertson D, Heiser J (2004) Evolution of coral reef fish Thalassoma spp. (Labridae). 1. Molecular phylogeny and biogeography. Marine Biology, 144, 369-375.

Cole AJ, Pratchett MS, Jones GP (2008) Diversity and functional importance of coral-feeding fishes on tropical coral reefs. Fish and Fisheries, 9, 286-307.

Craig MT (2008) The goldrim surgeonfish (Acanthurus nigricans; Acanthuridae) from Diego Garcia, Chagos Archipelago: first record for the central Indian Ocean. Zootaxa, 1850, 65-68.

Craig MT, Hastings PA (2007) A molecular phylogeny of the groupers of the subfamily Epinephelinae (Serranidae) with a revised classification of the Epinephelini. Ichthyological Research, 54, 1-17.

Craig MT, Eble JA, Bowen BW (2010) Origins, ages and population histories: comparative phylogeography of endemic Hawaiian butterflyfishes (genus Chaetodon). Journal of Biogeography, 37, 2125-2136.

Earl D, vonHoldt B (2012) STRUCTURE HARVESTER: a website and program for visualizing STRUCTURE output and implementing the Evanno method. Conservation Genetics Resources, 4, 359-361.

Edmands S (2002) Does parental divergence predict reproductive compatibility? Trends in Ecology \& Evolution, 17, 520-527.

Evanno G, Regnaut S, Goudet J (2005) Detecting the number of clusters of individuals using the software structure: a simulation study. Molecular Ecology, 14, 2611-2620.

Feddern HA (1968) Hybridization between the Western Atlantic Angelfishes, Holacanthus isabelita and H. ciliaris. Bulletin of Marine Science, 18, 351-382.

Fessler JL, Westneat MW (2007) Molecular phylogenetics of the butterflyfishes (Chaetodontidae): taxonomy and biogeography of a global coral reef fish family. Molecular Phylogenetics and Evolution, 45, 50-68.
Findley JS, Findley MT (2001) Global, regional, and local patterns in species richness and abundance of butterflyfishes. Ecological Monographs, 71, 69-91.

Fischer EA (1980) Speciation in the Hamlets (Hypoplectrus: Serranidae): a continuing enigma. Copeia, 1980, 649-659.

Frankham R, Ballou JD, Dudash MR et al. (2012) Implications of different species concepts for conserving biodiversity. Biological Conservation, 153, 25-31.

Frisch AJ, van Herwerden L (2006) Field and experimental studies of hybridization between coral trouts, Plectropomus leopardus and Plectropomus maculatus (Serranidae), on the Great Barrier Reef, Australia. Journal of Fish Biology, 68 1013-1025.

Gilbert KJ, Andrew RL, Bock DG et al. (2012) Recommendations for utilizing and reporting population genetic analyses: the reproducibility of genetic clustering using the program structure. Molecular Ecology, 21, 4925-4930.

Gosline WA (1948) Speciation in the fishes of the genus Menidia. Evolution, 2, 306-313.

Grant PR, Grant BR (2002) Unpredictable evolution in a 30-year study of Darwin's finches. Science, 296, 707-711.

Grant BR, Grant PR (2008) Fission and fusion of Darwin's finches populations. Philosophical Transactions of the Royal Society B: Biological Sciences, 363, 2821-2829.

Harmelin-Vivien M (1989) Implications of feeding specialization on the recruitment processes and community structure of butterflyfishes. Environmental Biology of Fishes, 25, $101-110$.

Hermansen JS, Sæther SA, Elgvin TO, Borge T, Hjelle E, Sætre GP (2011) Hybrid speciation in sparrows I: phenotypic intermediacy, genetic admixture and barriers to gene flow. Molecular Ecology, 20, 3812-3822.

van Herwerden L, Doherty PJ (2006) Contrasting genetic structures across two hybrid zones of a tropical reef fish, Acanthochromis polyacanthus (Bleeker 1855). Journal of Evolutionary Biology, 19, 239-252.

van Herwerden L, Davies CR, Choat JH (2002) Phylogenetic and evolutionary perspectives of the Indo-Pacific grouper Plectropomus species on the Great Barrier Reef, Australia. Journal of Fish Biology, 60, 1591-1596.

van Herwerden L, Choat JH, Dudgeon CL et al. (2006) Contrasting patterns of genetic structure in two species of the coral trout Plectropomus (Serranidae) from east and west Australia: introgressive hybridisation or ancestral polymorphisms. Molecular Phylogenetics and Evolution, 41, 420435.

Hettler WF (1968) Artificial fertilization among yellowfin and gulf menhaden (Brevoortia) and their hybrid. Transactions of the American Fisheries Society, 97, 119-123.

Hobbs J-PA, Salmond J (2008) Cohabitation of Indian and Pacific ocean species at Christmas and Cocos (Keeling) Islands. Coral Reefs, 27, 933-933.

Hobbs J-PA, Frisch AJ, Allen GR, van Herwerden L (2009) Marine hybrid hotspot at Indo-Pacific biogeographic border. Biology Letters, 5, 258-261.

Hobbs J-PA, van Herwerden L, Pratchett MS, Allen GR (2013) Hybridisation among coral reef butterflyfishes. In: Biology of Butterflyfishes (eds Pratchett MS, Berumen ML, Kapoor BG), pp. 48-69. CRC Press, Boca Raton, FL.

Hsu KC, Chen JP, Shao KT (2007) Molecular phylogeny of Chaetodon (Teleostei: Chaetodontidae) in the Indo-West 
Pacific: evolution in geminate species pairs and species groups. Raffles Bulletin of Zoology, s14, 77-86.

Huelsenbeck JP, Ronquist F (2001) MRBAYES: Bayesian inference of phylogenetic trees. Bioinformatics, 17, 754-755.

Jombart T, Devillard S, Balloux F (2010) Discriminant analysis of principal components: a new method for the analysis of genetically structured populations. BMC Genetics, 11, 94.

Kunte K, Shea C, Aardema ML et al. (2011) Sex chromosome mosaicism and hybrid speciation among tiger swallowtail butterflies. PLoS Genetics, 7, e1002274.

Littlewood DTJ, McDonald SM, Gill AC, Cribb TH (2004) Molecular phylogenetics of Chaetodon and the Chaetodontidae (Teleostei: Perciformes) with reference to morphology. Zootaxa, 779, 1-20.

MacCallum CJ, Nürnberger B, Barton NH, Szymura JM (1998) Habitat preference in the Bombina hybrid zone in Croatia. Evolution, 52, 227-239.

Mallet J (2005) Hybridization as an invasion of the genome. Trends in Ecology \& Evolution, 20, 229-237.

Mallet J (2007) Hybrid speciation. Nature, 446, 279-283.

Marie A, van Herwerden L, Choat J, Hobbs J-PA (2007) Hybridization of reef fishes at the Indo-Pacific biogeographic barrier: a case study. Coral Reefs, 26, 841-850.

Maruska KP, Peyton KA (2007) Interspecific Spawning between a Recent Immigrant and an Endemic Damselfish (Pisces: Pomacentridae) in the Hawaiian Islands. Pacific Science, 61, 211-221.

McMillan WO, Palumbi SR (1995) Concordant evolutionary patterns among Indo-West Pacific butterflyfishes. Proceedings of the Royal Society of London. Series B: Biological Sciences, 260, 229-236.

McMillan WO, Weigt LA, Palumbi SR (1999) Color pattern evolution, assortative mating, and genetic differentiation in brightly colored butterflyfishes (Chaetodontidae). Evolution, 53, 247-260.

Miyazawa S, Okamoto M, Kondo S (2010) Blending of animal colour patterns by hybridization. Nature Communications, 1, 66 .

Montanari SR, van Herwerden L, Pratchett MS, Hobbs J-PA, Fugedi A (2012) Reef fish hybridization: lessons learnt from butterflyfishes (genus Chaetodon). Ecology and Evolution, 2, 310-328.

Montanari SR, Gardner MG, Hobbs JPA, Pratchett MS, Bay LK, van Herwerden L (2013) Isolation and characterization of twenty microsatellite markers for the study of hybridization in butterflyfish of the genus Chaetodon. Conservation Genetics Resources, 5, 783-786.

Moritz C, Hoskin CJ, MacKenzie JB et al. (2009) Identification and dynamics of a cryptic suture zone in tropical rainforest. Proceedings of the Royal Society B: Biological Sciences, 276, 1235-1244.

Nichols JT (1918) An abnormal winter flounder and others. Copeia, 55, 37-39.

Nolte AW, Tautz D (2010) Understanding the onset of hybrid speciation. Trends in Genetics, 26, 54-58.

Nolte AW, Freyhof J, Tautz D (2006) When invaders meet locally adapted types: rapid moulding of hybrid zones between two species of sculpins (Cottus, Pisces) in the Rhine system. Molecular Ecology, 15, 1983-1993.

Norman JR (1934) A Systematic Monograph of the Flatfishes (Heterostomata). Natural History Section of the British Museum, London, UK.
Pereira MAM, Videira EJS (2005) Distribution and community structure of butterflyfishes (Pisces: Chaetodontidae) in Southern Mozambique. Western Indian Ocean Journal of Marine Science, 4, 39-46.

Pratchett MS (2005) Dietary overlap among coral-feeding butterflyfishes (Chaetodontidae) at Lizard Island, northern Great Barrier Reef. Marine Biology, 148, 373-382.

Pratchett MS (2013) Feeding preferences and dietary specialization among obligate coral-feeding butterflyfishes. In: Biology of Butterflyfishes (eds Pratchett MS, Berumen ML \& Kapoor B), pp. 140-179. CRC Press, Boca Raton, Florida.

Pratchett MS, Wilson SK, Berumen ML, McCormick MI (2004) Sublethal effects of coral bleaching on an obligate coral feeding butterflyfish. Coral Reefs, 23, 352-356.

Pratchett MS, Pradjakusuma O, Jones G (2006a) Is there a reproductive basis to solitary living versus pair-formation in coral reef fishes? Coral Reefs, 25, 85-92.

Pratchett MS, Wilson SK, Baird AH (2006b) Declines in the abundance of Chaetodon butterflyfishes following extensive coral depletion. Journal of Fish Biology, 69, 1269-1280.

Pratchett MS, Munday PL, Wilson SK et al. (2008) Effects of climate-induced coral bleaching on coral-reef fishes - ecological and economic consequences. In: Oceanography and Marine Biology: An Annual Review, vol. 46 (eds Gibson RN, Atkinson RJA, Gordon JDM), pp. 251-296. Taylor and Francis, Boca Raton, FL.

Pritchard JK, Stephens M, Donnelly P (2000) Inference of population structure using multilocus genotype data. Genetics, 155, 945-959.

Pyle RL, Randall JE (1994) A review of hybridization in marine angelfishes (Perciformes: Pomacanthidae). Environmental Biology of Fishes, 41, 127-145.

Randall JE (1956) Acanthurus rackliffei, a Possible Hybrid Surgeon Fish (A. achilles x A. glaucopareius) from the Phoenix Islands. Copeia, 1956, 21-25.

Randall JE, Allen GR, Steene R (1977) Five probable hybrid butterfly fishes of the genus Chaetodon from the central and western Pacific. Records of the Western Australian Museum, 6, 3-26.

Rao KS, Lakshmi K (1993) Scomberomorus lineolatus (Cuvier), an interspecific natural hybrid ( $S$. commerson (Lacépède) $\times S$. guttatus (Bloch \& Schneider)) off Visakhapatnam, India. Journal of Natural History, 27, 471-491.

Remington CL (1968) Suture-zones of hybrid interaction between recently joined biotas. In: Evolutionary Biology (eds Dobzhansky T, Hecht MK, Steere WC), pp. 321-428. Plenum Press, New York.

Rhymer JM, Simberloff D (1996) Extinction by hybridization and introgression. Annual Review of Ecology and Systematics, 27, 83-109.

Sano M (1989) Feeding habits of Japanese butterfyfishes (Chaetodontidae). Environmental Biology of Fishes, 25, 195-203.

Schultz LP, Smith RT (1936) Is Inopsetta ischyra (Jordan and Gilbert), from Puget Sound, Washington, a Hybrid Flatfish? Copeia, 1936, 199-203.

Seehausen O (2004) Hybridization and adaptive radiation. Trends in Ecology \& Evolution, 19, 198-207.

Singhal S, Moritz C (In press) Reproductive isolation between phylogeographic lineages scales with divergence. Arxiv Preprint arXiv:1301.4276v1.

Swenson NG, Howard DJ (2004) Do suture zones exist? Evolution, 58, 2391-2397. 
Taylor EB, Boughman JW, Groenenboom M, Sniatynski M, Schluter D, Gow JL (2006) Speciation in reverse: morphological and genetic evidence of the collapse of a three-spined stickleback (Gasterosteus aculeatus) species pair. Molecular Ecology, 15, 343-355.

Thompson WL (2004) Sampling Rare or Elusive Species: Concepts, Designs, and Techniques for Estimating Population Parameters. Island Press, Washington, District of Columbia.

Vines TH, Kohler SC, Thiel M et al. (2003) The maintenance of reproductive isolation in a mosaic hybrid zone between the fire-bellied toads Bombina bombina and B. variegata. Evolution, 57, 1876-1888.

Walsh PS, Metzger DA, Higuchi R (1991) Chelex-100 as a medium for simple extraction of DNA for PCR-based typing from forensic material. BioTechniques, 10, 506-513.

Willis BL, van Oppen MJH, Miller DJ, Vollmer SV, Ayre DJ (2006) The role of hybridization in the evolution of reef corals. Annual Review of Ecology, Evolution, and Systematics, 37, 489-517.

Willis PM, Symula RE, Lovette IJ (2013) Ecology, song similarity and phylogeny predict natural hybridization in an avian family. Evolutionary Ecology, 00, 1-24.

Wilson SK, Graham NAJ, Pratchett MS (2013) Susceptibility of butterflyfish to habitat disturbance: do 'chaets' ever prosper? In: Biology of Butterflyfishes (eds Pratchett MS, Berumen ML, Kapoor BG), pp. 226-240. CRC Press, Boca Raton, FL.

Wirtz P (1999) Mother species-father species: unidirectional hybridization in animals with female choice. Animal Behaviour, 58, 1-12.

Yaakub SM, Bellwood DR, van Herwerden L, Walsh FM (2006) Hybridization in coral reef fishes: Introgression and bi-directional gene exchange in Thalassoma (family Labridae). Molecular Phylogenetics and Evolution, 40, 84-100.

Yaakub S, Bellwood D, van Herwerden L (2007) A rare hybridization event in two common Caribbean wrasses (genus Halichoeres; family Labridae). Coral Reefs, 26, 597-602.

Yabuta S (1997) Spawning migrations in the monogamous butterflyfish Chaetodon trifasciatus. Ichthyological Research, 44, 177-182.

S.R.M., J.P.A.H., M.S.P. and L.vH. designed the research project. S.R.M. and J.P.A.H. conducted field observations and collected samples for genetic analyses. S.R.M. conducted molecular genetics laboratory work and analysed data. S.R.M., J.P.A.H., M.S.P., L.K.B. and L.vH. wrote the article.

\section{Data accessibility}

All sequence data were uploaded to GenBank [Chaetodon guttatissimus group: KF609281-KF609366, Chaetodon trifasciatus group - Montanari et al. (2012): JQ012110JQ012216].
All ecological and behavioural data for both hybrid groups (this study and Montanari et al. 2012), as well as microsatellite genotypes, sequence alignment and phylogenetic tree files for the C. guttatissimus group were deposited on Dryad (doi:10.5061/dryad.mh50q).

Microsatellite genotypes for the $C$. trifasciatus group (Montanari et al. 2012) were deposited on Dryad (doi:10.5061/dryad.20fc5v4j).

\section{Supporting information}

Additional supporting information may be found in the online version of this article.

Fig. S1 Pairing behaviour (A), mtDNA haplotype network (B), scatterplot of DAPC (C) and STRUCTURE admixture plot (D) for the C. trifasciatus group (redrawn from Montanari et al. 2012).

Fig. S2 $\Delta k$ plots (Evanno et al. 2005) from STRUCTURE HARVESTER (Earl \& vonHoldt 2012) showing a sharp decline in the rate of change of the log probability of data for values of $k>2$.

Fig. S3 Posterior probabilities, based on microsatellite data from Montanari et al. (2012), of individuals of the Chaetodon trifasciatus group belonging to six classes: pure parental species, $\mathrm{F} 1$ or $\mathrm{F} 2$ hybrids and backcrosses $(B x)$ in either direction.

Data S1 Material and Methods.

Table S1 Summary statistics for 20 microsatellite loci (Montanari et al. 2013) used to genotype the Chaetodon guttatissimus group: for each adequately sampled population we report sample size $(n)$, number of alleles $\left(N_{\mathrm{a}}\right)$, private alleles $\left(P_{\mathrm{a}}\right)$, average inbreeding coefficient $\left(F_{\mathrm{IS}}\right)$, observed $\left(H_{\mathrm{O}}\right)$ and expected $\left(H_{\mathrm{E}}\right)$ heterozygosities, and probability of departure from HWE (p).

Table S2 Sample sizes, cyt b number of haplotypes (nh), haplotype (h) and nucleotide $(\pi)$ diversities and intra-population gene diversity based on 20 microsatellite loci (1-Q Inter).

Table S3 Pairwise population comparisons in the Chaetodon guttatissimus group.

Table S4 Raw and ENA-corrected (Chapuis \& Estoup 2007) population differentiation and estimator of actual differentiation (Jost 2008) $\left(D_{\text {est }}\right)$ presented locus-by-locus and as a mean over all loci. 